\title{
Understanding the Impact of Social Media Educational Advertising on Professional Course Students
}

\author{
Dr. Tarakeswara Rao Ippili* \\ Assistant Professor, Dept. of Journalism and Mass Communication Central University of Karnataka, \\ Karnataka, India
}

*Corresponding Author: Dr. Tarakeswara Rao Ippili, Assistant Professor, Dept. of Journalism and Mass Communication Central University of Karnataka, Karnataka, India

\begin{abstract}
This examination is an endeavor to research the impact of social media educational advertisements on professional course students. The main aim of this research was to find out the attitude and behaviour change in higher education students of Hyderabad regarding advertisements on social media. Descriptive Survey method was used in this study. The sample consists of 300 professional course students from Hyderabad district. The investigator used a stratified random sampling technique for selecting the sample. A questionnaire was constructed for the professional course students to find out the opinions of students on the impact of educational advertisements through social media on students. Data was collected through different means some of them are 1) Personal administration of questionnaire with 300 professional students; 2) Secondary data collected from websites and journals; and 3) Informal interview, survey with individuals who use to follow ads. The data were analyzed using various statistical methods like Mean, Standard Deviation, $t$ test and F-test (ANOVA) by SPSS package. The mean score obtained by different groups is compared across the variables like age, gender, caste, religion, family income, size of the family, nativity, educational qualifications, and occupation. The results are discussed in light of previous research done.
\end{abstract}

Keywords: Social Media, Advertisements, Professional Course, Students, Behaviour.

\section{INTRODUCTION}

In the present world, Life is very difficult to consider without mass media. Media informs, entertain, educate, aware and invade us. Media are one of the major factors of social change. New media has its impact and influence on society and culture. Social media evolution has deeply transformed the communication landscape picture (Steven, 2011). Social media exploded as a category of online discourse which enables people to create contents, share them, bookmark them and network at a prodigious rate (Jha and Bharadwaj, 2012). Social media is a phenomenon that has drawn a lot of attention both to companies and individuals interacting in the networking landscape. However, when it comes to giving a clear definition of what social media is, the understanding of the term is very minimal. Managers and academic researchers seem to differ on how social media differ from interchangeable related concept web 2.0 and User Generated Content (Kaplan and Haenlein, 2010). Advertising is the means of promoting, informing as well as influencing the general public to purchase an item or services through visual or oral messages.

The advertising message is considered as an important component in the advertising communication process. It is the idea, demean our, picture or other information that the advertiser wish to pass on to the intended interest group. An ideal advertising message should command and draw attention, hold the interest, arouse desire for possession of the product, and elicit an action (Gupta, 2012). The adequacy of an advertising message depends to an enormous degree on its visual substance. The advertiser must find an intrigue, appeal, theme, idea or one kind of selling proposition.

Advertising is often considered within a framework that identifies advertising appeals as basically either rational or emotional (Solomon, 1992). An advertising claim alludes to the approach used by an advertiser to draw in the consideration or interest of the purchaser and influence their sentiments towards the product, service or idea. The visual components used in the advertisements not only pass the information but also reinforce the advertising claims. Kotler (1997) pointed out in his study that advertising appeal is the theme of an advertisement. To make the audience receive a necessary 
message, advertisers have to put some driving power into the message, this driving power is an appeal. Every advertising appeal represents an attraction, which arouses consumers' desires (Lin, 2011). It ensures good connectivity and trust between the advertiser and the consumers and adds value to the product. Since the advertiser expects to create a favourable attitude about the product which will lead to positive actions in the mind of the consumer, a unique visual attribute is required to improve the taste and acknowledgement of the customer about the product in this manner advertised.

The rationale for this study was motivated by a personal interest in social media. The social media advancement has deeply transformed the communication landscape picture. Social media is the name of the social networking sites such as Facebook, Twitter, LinkedIn, Myspace, and blogs these websites are the important websites for companies so they can maintain direct relationships with their customers. Nazeer (2017) investigated that companies have built entire departments who design and control social media according to their companies needs and promotional activities. Social media is different from traditional media because it is generated by users of these websites and users have more control over its use and they also generate content by themselves at times. Tarakeswara (2018) revealed that these emergent new forms of user-generated content are transforming mediated communication in the $21^{\text {st }}$ century and students of social networks will come away with a fresh understanding of how user-generated content is fundamentally reshaping, mediated communication on multiple levels.

Kolan and Dzandza (2017) argued that the nature of social media as a useful servant but a dangerous master" and a two-edge sword has been revealed in the findings of the study that, despite the benefits that students can harness from social media networks such as sharing of information, building relationship, partaking in group discussions from near and far among others, there is to some extent addiction and distraction of attention caused by the use of social media which could have serious consequences on the academic life of students. According to Tuten (2008), if social media became a part of a promotional campaign it can increase brand awareness and it can also improve its image and reputation. He has also mentioned that the traffic to a retail website can be increased, there could be an increment in the sales and overall basic advertisements strategy could be enhanced. To conduct information searches about a product and to make purchasing decisions customers are attracting to several types of social media on the internet.

\section{NEED AND IMPORTANCE OF THE STUDY}

Social media refers to all applications and websites or blogs that enable people around the globe to interconnect via the internet, chat, and share content, video call among many other functionalities it offers to its users. For a person to be a member of any social media, he or she has to first signup and then sign in to access content and be able to share and chat with other users of that social media platform. The use of social media has both negative and positive impacts on youth today. The researcher focus to bring into light that the impacts of social media specifically on the youth of this present generation. These impacts include both positive and negative. The positive impacts of social media on the youth today include making them update on the events happening around the globe and also enables the network and stay connected with their fellow youth and friends without physical meetings. Additionally, youth can create pages and groups in the social media platforms based on their professions, faith among other dimensions of their lives and this leads to more connections being built and more opportunities being opened for their respective disciplines. This can even lead to more employment opportunities being created for unemployed youths. Hence, the present study examines the impact of educational advertisements through social media on students in Hyderabad.

This study aims to examine the attitude of professional course students towards the impact of educational advertisements through social media on students targeted advertising on their homepage. It will measure the behavioural adaptations and changes in user's attitude towards these advertisements. There is a rise in advertisements of online social networks, and perception of professional course students regarding targeted messages on a popular network like Facebook is not known to a greater extent. Marketers should be enabled to reach users with relevant advertisements and personalized messages. Such targeting will increase the value of advertising for both advertisers and social network users. 


\subsection{Research Objectives}

1. To study the impact of educational advertisements through social media on students of the professional course in Hyderabad.

2. To study the significant differences in the perceptions of the students towards the impact of educational advertisements through social media based on their socio-economic backgrounds viz., age, gender, caste, religion, family income, size of the family, nativity, qualification and occupation.

3. To find remedial measures to benefit the professional course students more from the provision.

\subsection{Literature Reviews}

There are many studies about the impact of social media on the student's academic performance and mental behaviour. There are few studies conducted over the effect of advertisements through social media on student's behaviour. For example, Kuppuswamy and Narayan (2010) reviewed on "The Impact of Social Networking Websites on the Education of Youth". Social networking websites like Orkut, Facebook, Myspace and YouTube are becoming more and more popular and has become part of daily life for an increasing number of people. Because of their features, young people are attracted to social networking sites. The study argues that these social networking websites distract students from their studies, but these websites can be useful for education based on sound pedagogical principles and proper supervision by the teachers. Tarakeswara, R. I. (2017) revealed that social networking sites are a boon and curse for the society, young people who share personal experiences online taking steps to protect their own and other identities.

Fauser et al. (2011) argue that though communication is the core dimension of social media networks, not all platform categories are equally suitable for all marketing objectives because most of the platforms are not equally well suited for information, collaboration, and even for cultivating relationships. Ali Sarıkaş et al., (2016) studied on "Impact of Advertisements in Social Media on Purchasing Behaviour of Associate Students". The researchers discussed that the impact of advertisements on social media, commonly used by university students, on the purchasing behaviour of consumers was investigated. Shabnoor Siddiqui and Tajinder Singh (2016) argued that the youth discussed more on social media with a positive and negative effect, focusing on a particular field like business, education, society and youth. And one more thing they described how these media will broadly affect society. Lukka and James (2014) in a study revealed that products can be advertised through Facebook in a personalized manner. Advertisers while placing their ads on Facebook can customize their information to their specific audience. They can target individuals based on mutual interests and demographic information.

There is a correlation between social media usage and academic performance of students in universities. There have been various views and opinions which recognize four major advantages of social media use in higher education. These include; enhancing relationship, improving learning motivation, offering personalized course material, and developing collaborative abilities (Wheeler, Yeomans and Wheeler, 2008; Rifkin, Longnecker, Leach and Ortia, 2009). Akshadeep Bhardwaj and Vinay Avasthi, Sam Goundar (2017) studied on "Impact of Social Networking on Indian Youth - A Survey". The extensive use of social networking in India has been on the rise among the new generation youths. In today's world, life cannot be imagined without Facebook, YouTube, Instagram, What's App, Linkedin or Twitter accounts and online handles.

\section{MeThodology}

The investigator followed the survey method of descriptive research. For this investigation, the questionnaire had been considered as a suitable tool for the collection of data. The present investigation is collected from the perceptions of professional course students towards the impact of educational advertisements through social media on students, a questionnaire was constructed and administered to find out the results from the selected target group.

According to the research, the survey will be conducted amongst the (300) students one who belongs to UG to PG courses which are located in Hyderabad district of Telangana, India. The variables are studied like, Age, Gender, Caste, Religion, Family Income, Size of the family, Nativity, Qualification and Occupation. 


\subsection{Statistical Techniques Used}

The investigation has been carried out by the descriptive statistical analysis, such as calculating measures of central tendency like Mean and calculating measures of dispersion like Standard Deviation. For testing the null hypothesis, the ' $t$ ' - test and Analysis of Variance have been used by the investigator. The ' $t$ ' test is used to test the null hypothesis when the data is correlated from matched groups. Analysis of (ANOVA) variance is used to find out the effect, if any, of the variables studied.

\section{Data ANAlysis AND Results}

Table1. Mean, SD, and 'F'/'t' Values on the perceptions of Professional course students based on their SocioEconomic variables towards the Impact of Educational Advertisements through Social Media on Youth

\begin{tabular}{|c|c|c|c|c|c|}
\hline Variable & Category & Mean & S.D. & F/t-value & p-value \\
\hline \multirow{4}{*}{ Age } & $15-20$ & 22.42 & 7.10 & \multirow{4}{*}{$6.77 * *$} & \multirow{4}{*}{0.00} \\
\hline & $21-25$ & 22.87 & 6.51 & & \\
\hline & $26-30$ & 20.43 & 3.69 & & \\
\hline & More than 30 & 19.67 & 4.03 & & \\
\hline \multirow{2}{*}{ Gender } & Male & 24.05 & 7.00 & \multirow{2}{*}{$6.74 * *$} & \multirow[b]{2}{*}{0.00} \\
\hline & Female & 20.83 & 6.08 & & \\
\hline \multirow{4}{*}{ Caste } & $\mathrm{OC}$ & 23.33 & 6.54 & \multirow{4}{*}{$8.12 * *$} & \multirow{4}{*}{0.00} \\
\hline & $\mathrm{BC}$ & 21.94 & 6.79 & & \\
\hline & $\mathrm{SC}$ & 19.54 & 6.35 & & \\
\hline & ST & 18.00 & 3.12 & & \\
\hline \multirow{3}{*}{ Religion } & Hindu & 24.90 & 6.76 & \multirow{3}{*}{$4.19 *$} & \multirow{3}{*}{0.02} \\
\hline & Muslim & 22.40 & 6.65 & & \\
\hline & Christian & 19.64 & 7.48 & & \\
\hline \multirow{3}{*}{$\begin{array}{l}\text { Family } \\
\text { Income }\end{array}$} & Less than Rs. 1 Lakh & 23.08 & 6.66 & \multirow{3}{*}{$4.89^{*}$} & \multirow{3}{*}{0.01} \\
\hline & Rs. 1 Lakh -Rs.5 Lakh & 21.39 & 6.62 & & \\
\hline & More than Rs. 5 Lakh & 22.26 & 6.89 & & \\
\hline \multirow{5}{*}{$\begin{array}{l}\text { Size of } \\
\text { the Family }\end{array}$} & 2 & 24.18 & 6.73 & \multirow{5}{*}{$5.97 * *$} & \multirow{5}{*}{0.00} \\
\hline & 3 & 21.86 & 6.33 & & \\
\hline & 4 & 23.10 & 6.79 & & \\
\hline & 5 & 21.06 & 6.51 & & \\
\hline & More than 5 members & 19.55 & 5.85 & & \\
\hline \multirow{3}{*}{ Nativity } & Rural & 22.64 & 7.12 & \multirow{3}{*}{$0.48^{\mathrm{NS}}$} & \multirow{3}{*}{0.70} \\
\hline & Semi Urban & 21.71 & 5.87 & & \\
\hline & Urban & 22.26 & 6.60 & & \\
\hline \multirow{4}{*}{ Qualification } & Under Graduation & 22.23 & 6.67 & \multirow{4}{*}{$3.40^{*}$} & \multirow{4}{*}{0.02} \\
\hline & Post-Graduation & 22.34 & 6.71 & & \\
\hline & M.Phil. / Ph.D. & 25.00 & 7.67 & & \\
\hline & Professional Courses & 27.20 & 6.92 & & \\
\hline \multirow{4}{*}{ Occupation } & Job & 22.72 & 5.81 & \multirow{4}{*}{$3.49^{*}$} & \multirow{4}{*}{0.02} \\
\hline & Business & 24.58 & 6.95 & & \\
\hline & Self Employed & 23.86 & 6.46 & & \\
\hline & Unemployed & 21.93 & 6.84 & & \\
\hline
\end{tabular}

**Significant at $0.01, *$ Significant at 0.05 level and NS: Not Significant

The above table revealed that, the mean perceptual scores of students towards the impact of educational advertisements through social media on students. The mean perceptual scores for below 15-20 years age group was 22.42, for 21 to 25 years age group students was 22.87 and it was for 2630 years age group students was 20.43, whereas it is for the More than 30 years age group students was 19.67. The Standard Deviations for 15-20, 21-25, 26-30 and More than 30 years age group students were 7.10, 6.51, 3.69 and 4.03 respectively. The ' $F$ '-value was 6.77 and the p-value was 0.00 , which was statistically significant at 0.05 level. This shows that there is a significant difference among the perceptions of students based on their age group and 21-25 years age group students perceived high towards the impact of educational advertisements through social media on students than that of 15-20, 26-30 and more than 30 years age group students.

Gender revealed that the mean perceptual score of male students was 24.05 , whereas it is for the female category students was 20.83. The Standard Deviations for male and female students were 7.00 
and 6.08 respectively. The derived $\mathrm{t}$ - value was 6.74 and the p-value was 0.00 which was statistically significant at 0.01 level. This shows that there is a significant difference between the perceptions of male and female students and male category students perceived high towards the impact of educational advertisements through social media on students than that of female category students.

About Caste, the mean perceptual scores for OC caste students was 23.33, for BC caste students were 21.94 and it was for SC caste students was 19.54, whereas it was for ST caste students was 18.00. The Standard Deviations for OC, BC, SC and ST caste students were 6.54, 6.79, 6.35 and 3.12 respectively. The ' $F$ '-value was 8.12 and the p-value was 0.00 , which was statistically significant at 0.01 level. This shows that there is a significant difference among the perceptions of students based on their caste and OC caste students perceived high towards the impact of educational advertisements through social media on students than that of BC, SC and ST caste students.

Concerning Religion, the mean perceptual scores for Hindu religion students was 24.90, and it was for Muslim religion students was 22.40, whereas it was for Christian religion students was 19.64. The Standard Deviations for Hindu, Muslim and Christian religion students were 6.65, 6.76 and 7.48 respectively. The ' $F$ '-value was 4.19 and the p-value was 0.02 , which was statistically significant at 0.05 level. This shows that there is a significant difference among the perceptions of students based on their religion and Hindu religion students perceived high towards the impact of educational advertisements through social media on students than that of Christian and Muslim religion students.

In the case of family income, the mean perceptual scores for less than Rs. 1 lakh family income students was 23.08, and it was for Rs. 1 lakh to Rs. 5 lakh family income of students was 21.39, whereas it was for more than Rs. 5 lakh family income of students was 22.26. The Standard Deviations for less than Rs. 1 lakh, Rs. 1 lakh to 5 lakhs and More than Rs. 5 lakhs family income students were 6.66, 6.62 and 6.89 respectively. The ' $F$ '-value was 4.89 and the p-value was 0.01 , which was statistically significant at 0.05 level. This shows that there is a significant difference among the perceptions of students based on their family income and less than Rs. 1 lakh family income of students perceived high towards the impact of educational advertisements through social media on students than that of Rs. 1 lakh to 5 lakhs and More than Rs. 5 lakhs family income of students.

Concerning Size of the family, the mean perceptual scores for 2 members of the family size of students was 24.18 , for 3 members of the family size of students was 21.86 and it was for 4 members of the family size of students was 23.10, and for five members of the family size of students was 21.06, whereas it was for more than five members of the family size of students was 1955 . The Standard Deviations for 2, 3, 4, 5 and more than 5 member of the family size of students were 6.73, $6.33,6.79,6.51$ and 5.85 respectively. The ' $F$ '-value was 5.97 and the p-value was 0.00 , which was statistically significant at 0.01 level. This shows that there is a significant difference among the perceptions of students based on their family size and two members of the family size of students perceived high towards the impact of educational advertisements through social media on students than that of 3, 4, 5 and more than 5 members of the family size of students.

About Nativity, the mean perceptual scores for rural area students was 22.64, and it was for SemiUrban area students was 21.71, whereas it was for urban area students was 22.26. The Standard Deviations for rural, semi-urban and urban area students were 7.12, 5.87 and 6.60 respectively. The ' $F$ '-value was 0.48 and the p-value was 0.70 , which was statistically not significant. This shows that there is no significant difference among the perceptions of students based on their Nativity and they perceived similar opinion towards the impact of educational advertisements through social media on students.

In the case of Qualification, the mean perceptual scores for Under Graduation students was 22.23, for Post-Graduation students were 22.34 and it was for M.Phil./Ph.D. qualified students was 25.00, whereas it was for Professional course students was 27.20. The Standard Deviations for Under Graduation, Post-Graduation, M.Phil./Ph.D. and Professional course students were 6.67, 6.71, 7.67 and 6.92 respectively. The ' $F$ '-value was 3.40 and the p-value was 0.02 , which was statistically significant at 0.05 level. This shows that there is a significant difference among the perceptions of students based on their qualification and Professional course students perceived high towards the impact of educational advertisements through social media on students than that of Under Graduation, Post-Graduation and M.Phil./Ph.D. qualified students. 
Concerning occupation, the mean perceptual scores for students who are employed was 22.72, and for s students who are doing business was 24.58 and it was for self-employed students was 23.86, whereas it was for unemployed students was 21.93. The standard deviations for job, business, selfemployed and unemployed students were 5.81, 6.95, 6.46 and 6.84 respectively. The ' $F$ '-value was 3.49 and the p-value was 0.02 , which was statistically significant at 0.05 level. This shows that there is a significant difference among the perceptions of students based on their occupation and business occupation of students perceived high towards the impact of educational advertisements through social media on students than that of the rest of occupations of the students.

\section{CONCLUSION}

It was noticed that a significant difference was found among the perceptions of students based on their age, gender, caste, religion, family income, size of the family, qualification and occupation towards the impact of educational advertisements through social media on students. According to their age, 21 to 25 years age group students perceived high than that of 1-20, 26-30 and more than 30 years age group students, basing on their gender, male category students perceived high than that female category students, according to their caste, OC category students perceived high than that of BC, SC and ST category students, for their religion, Hindu religion students perceived high than that of the rest, about the size of the family, two members of the family size of students perceived high than that of 3, 4, 5 and more than 5 members of the family size of students, according to their qualification, professional course students perceived high than that of UG, PG and M.Phil./Ph.D. qualified students and also according to their occupation, business occupation of students perceived high than that of job, self-employed and unemployed of the students.

No significant were found between the perceptions of students based on their nativity towards the impact of educational advertisements through social media on students and they perceived similar opinion. Parents should guide and advise their children on current matters like the usage of social media and warn them of its negative impacts on them when misused or overused. The education curriculum also should be revised so that it can include social media studies in its disciplines to alert students that they need to be careful in their social media usage. It is further recommended that social media should be seen as the prophet to media solution to advertising communications issues, but rather, the choice of social media should be made in the understanding of the fact that it is best used in conjunctions with other advertising communications.

\section{REFERENCES}

[1] Akashdeep. B., Avasthi, V., \& Goundar, S. (2017). Impact of Social Networking on Indian Youth: A Survey, International Journal of Electronics and Telecommunications, 7(1):41-51.DOI: 10.6636/IJEIE. 201709.7(1).05)

[2] Ali, S., Nuray, O. C., Mehmet, T., Ayse, Y., Necla, T., \& Zuhal, P. (2016). Impact of Advertisements in Social Media on Purchasing The behaviour of Associate Students, Journal of Educational and Instructional Studies, 6(4), 32-39.

[3] Fauser, S. G., Wiedenhofer, J. and Lorenz, M. (2011). Touchpoint social web: An explorative study about using the social web for influencing high involvement purchase decisions, 9(1).

[4] Gupta, R. (2012). Advertising Principles and Practices: With 17 Recent Indian Cases, New Delhi, S. Chand Publishers.

[5] Jha, V. \& Bhardwaj, R. (2012). The new marketing renaissance: Paradigm shift in social networks. International Journal of Engineering and Management Sciences, 3(3), pp. 384-387. Retrieved from www.scienceandnature.org.

[6] Kaplan, A. M. and Haenlein, M. (2010). Users of the World, Unite! The Challenges and Opportunities of Social Media. Business Horizons, 53(1), 59-68. DOI: 10.1016/j.bushor.2009.09.003

[7] Kolan, J. B., and Dzandza, P. E. (2017). Effect of Social Media on Academic Performance of Students in Ghanaian Universities: A Case Study of University of Ghana, Legon Library Philosophy and Practice

[8] Kotler, P. (1997). Marketing Management: Analysis, Planning, Implementation, and Control. $9^{\text {th }}$ edition, Prentice-Hall, Upper Saddle River.

[9] Kuppuswamy, S., \& Narayan, P. (2010). The Impact of Social Networking Websites on the Education of Youth, International Journal of Virtual Communities and Social Networking, 2:1, 67-79. DOI: 10.4018 /jvcsn.2010010105 
[10] Lin, L. Y. (2011). The impact of advertising appeals and advertising spokespersons on advertising attitudes and purchase intentions. African Journal of Business Management, 5(21), 8446-8457. DOI: 10.589/AJBM11.925

[11] Lukka, V. \& James, P. T. J. (2014). Attitudes toward Facebook Advertising. Journal of Management and Marketing Research. 14, 1-26.

[12] Nazeer, J. (2017). Impact of Social Media Advertisements on University Students. Arts and Social Science Journal, 8:4, DOI: 10.4172/2151-6200.1000290

[13] Rifkin, W., Longnecker, N., Leach, J., \& Ortia, L. (2009). Motivate students by having them publish in new media: an invitation to Science Lectures to share and test. A paper presented at the motivating Science Undergraduates: Ideas and Interventions, UniServe Science Proceedings. Retrieved from citeseerx.ist.psu. edu

[14] Shabnoor, S. \& Tajinder, S. (2016). Social Media its Impact with Positive and Negative Aspects. International Journal of Computer Applications Technology and Research, 5(2), 71-75.

[15] Solomon, M. R. (1992). Consumer behaviour. Boston: Allyn \& Bacon.

[16] Steven, M. Edwards, (2011). A Social Media Mindset, Journal of Interactive Advertising, 12:1, 1-3, DOI: $10.1080 / 15252019.2011 .10722186$

[17] Tarakeswara, R. I. (2017). Social Media Impact on Acharya Nagarjuna University Students: A Survey Analysis. International Journal of Research in Economics and Social Sciences, 7(12), 787-804.

[18] Tarakeswara, R. I. (2018). Social Media networking sites usage among girl students: A Survey analysis. International Journal of Management and Social Sciences Research, 7(1), 23-34.

[19] Tuten, L. T. (2008). Advertising 2.0: Social Media Marketing in a Web 2.0 World. Praeger Publisher, West, Westport, CT.

[20] Wheeler, A., Yeomans, P., \& Wheeler, D. (2008). The good, the bad and the Wiki: Evaluating studentgenerated content for collaborative learning. British Journal of Educational Technology, 39(6), 987-995. doi: 10.1111/j.1467-8535.2007.00799.x.

Citation: Dr. Tarakeswara Rao Ippili. "Understanding the Impact of Social Media Educational Advertising on Professional Course Students". International Journal of Media, Journalism and Mass Communications (IJMJMC), vol 6, no. 3, 2020, pp. 14-20 doi: http://dx.doi.org/10.20431/2454-9479.0603002.

Copyright: (C) 2020 Authors. This is an open-access article distributed under the terms of the Creative Commons Attribution License, which permits unrestricted use, distribution, and reproduction in any medium, provided the original author and source are credited. 